\title{
Periodontitis Is Associated With Preeclampsia in Pregnant Women
}

\author{
A. Contreras, ${ }^{*}$ J.A. Herrera, ${ }^{\dagger}$ J.E. Soto, ${ }^{*}$ R.M. Arce, ${ }^{*}$ A. Jaramillo, ${ }^{*}$ and J.E. Botero*
}

Background: Recent investigations have demonstrated a positive association between periodontitis and pregnancy complications. The purpose of this study was to determine the effect of periodontitis and the subgingival microbial composition on preeclampsia.

Methods: A case-control study was carried out in Cali, Colombia that included 130 preeclamptic and 243 nonpreeclamptic women between 26 to 36 weeks of pregnancy. Sociodemographic data, obstetric risk factors, periodontal status, and subgingival microbial composition were determined in both groups. Preeclampsia was defined as blood pressure $\geq 140 / 90 \mathrm{~mm} \mathrm{Hg}$, and $\geq 2+$ proteinuria, confirmed by $0.3 \mathrm{~g}$ proteinuria/24 hours of urine specimens. Controls were healthy pregnant women. Odds ratios (ORs) for periodontitis and subgingival microbiota compositions were calculated.

Results: A total of 83 out of 130 preeclamptic women (63.8\%) and 89 out of 243 controls (36.6\%) had chronic periodontitis (OR: 3.0; 95\% confidence interval (CI): 1.91 to 4.87 ; $P<0.001)$. Clinical attachment loss increased in the case group $(4.0 \pm 0.10 \mathrm{~mm})$ compared to the control group $(3.0 \pm 0.08$ $\mathrm{mm})(P<0.001)$. The average newborn birth weight from preeclamptic mothers was $2.453 \mathrm{~g}$, whereas in controls was $2.981 \mathrm{~g}(P<0.001)$. Two red complex microorganisms, Porphyromonas gingivalis and Tannerella forsythensis, and the green complex microorganism Eikenella corrodens were more prevalent in the preeclamptic group than in controls $(P<0.01)$.

Conclusions: Chronic periodontal disease and the presence of $P$. gingivalis, $T$. forsythensis, and $E$. corrodens were significantly associated with preeclampsia in pregnant women. Further research is needed to establish pathogenic mechanisms of active periodontal disease and subgingival periodontopathogens related to preeclampsia development. J Periodontol 2006; 77:182-188.

\section{KEY WORDS}

Bacteria; case-control study; infection; periodontitis; preeclampsia.

\footnotetext{
* Periodontal Medicine Research Group, Department of Periodontology, School of Dentistry, University of Valle, Cali, Colombia.

$\dagger$ Department of Family Medicine, School of Medicine, University of Valle.
}

$\mathrm{P}$ reeclampsia is a rapidly progressive condition observed during pregnancy, characterized by hypertension and the presence of protein in the urine. At least 3\% to $5 \%$ of pregnancies are affected, resulting in high morbidity and mortality around the world. ${ }^{1}$ Altered vascular-related conditions have been proposed as the main pathogenic mechanisms leading to placental endothelial damage. ${ }^{2-4}$ Preeclampsia is also associated with short- and long-term abnormal cytokine responses in the mother and the fetus, related to high circulating levels of tumor necrosis factor (TNF)- $\alpha$, interleukin (IL)-10, and IL-6. ${ }^{5}$ Thus, the result is an inflammatory vascular damage that induces preeclampsia and other pregnancy complications such as low birth weight (LBW) or preterm births. Understanding the initiating etiologic factors may serve to properly design preventive and therapeutic strategies.

It has been proposed that subclinical infections may contribute in the etiology and pathogenesis of several atherosclerotic and systemic diseases. ${ }^{6}$ Higher incidences of bacteriurias, urinary tract infections, and/or other asymptomatic diseases have also been reported in pregnant women with preeclampsia. ${ }^{7-11}$ Periodontal disease is also a chronic infection that exposes the host to microbial challenges (antigens and virulence factors) for extended time periods. ${ }^{6,12}$

Most studies addressing the relationship between periodontitis and adverse pregnancy outcomes have shown that women with poor oral conditions may 
be at risk of premature birth. ${ }^{13,14}$ However, other studies have found no relationship between periodontal health and adverse pregnancy outcomes. ${ }^{15}$ In a prospective study, severe periodontal disease was a high risk factor for preterm birth in pregnant women before 32 weeks of gestation. ${ }^{16}$ A recent study in 763 pregnant women showed that preeclamptic women have more periodontitis than non-preeclamptic women. ${ }^{17}$ Although infection of any kind in pregnant women represents a risk for adversities in the developing fetus, periodontal disease may have a significant role in the pathogenesis of preeclampsia.

Recently, Herrera et al. ${ }^{18}$ established that the early identification of risk factors, the administration of nutritional supplements, and the treatment of asymptomatic infections lowered the preceding incidences of preeclampsia in 15,354 pregnant women from low socioeconomic status in Colombia, where preeclampsia is a prevalent disease (8\%). These authors hypothesized that chronic subclinical infections may cause increased maternal cytokine levels sufficient to affect vascular endothelial function, thereby making pregnant women prime individuals for the subsequent development of preeclampsia. Therefore, the purpose of this study was to investigate the possible association between periodontal disease and preeclampsia in a sample of Colombian pregnant women.

\section{MATERIALS AND METHODS}

\section{Study Population}

A case-control methodology was used in this study, previously approved by the Institutional Review Boards (IRBs) of the University of Valle, Cali, Colombia. All women signed a written informed consent at the first interview. In the case of underage subjects $(\leq 18$ years old), the corresponding parent signed the authorization for study inclusion. Women with preeclampsia attending the University Hospital (HUV) and controls attending a basic health facility (Siloe health center) were enrolled in this study between March 2003 and October 2004.

\section{Clinical Examination}

A clinical record regarding personal information, marital status, race, education level, number of pregnancies, and medical examination was completed for all patients. Preeclampsia was defined as high protein levels in urine (2+ proteinuria), confirmed by at least $0.3 \mathrm{~g}$ proteinuria/24 hours and hypertension $(\geq 140 /$ $90 \mathrm{mmHg}$ ). All women were at 26 to 36 weeks of gestational age. Women with no health complications were assigned to the non-preeclamptic group (controls). Previous consumption of antibiotics (3 months before study inclusion) and periodontal treatment, gestational diabetes, non-confirmed preeclampsia, hypertension before pregnancy, malaria, hemolytic anemia, elevated liver enzymes, and low platelet count (HELLP) syndrome, and any other infection other than periodontitis served as exclusion criteria. Low birth weight was assumed when $<2,500 \mathrm{~g}$.

Clinical measures of periodontal health were determined in all subjects, including sulcus/probing depth (PD), gingival recession, and periodontal clinical attachment loss (CAL). Sulcus/probing depth was measured in millimeters with a UNC-15 periodontal probe at six sites per tooth as the distance from gingival margin to periodontal attachment. Gingival recession was determined by measuring the distance from the cemento-enamel junction to the gingival margin in millimeters and rounded down to the next millimeter. The clinical attachment loss was calculated from recession and probing depth measures and represents the distance in millimeters from cemento-enamel junction to periodontal ligament attachment. Periodontal disease was classified according to the American Academy of Periodontology. ${ }^{19}$ Patients were classified as having gingivitis if no pocketing $(\leq 3 \mathrm{~mm})$, no bleeding on probing, and no gingival inflammation were present. Chronic periodontitis was defined when two or more sites showed pocket formation ( $\geq 4 \mathrm{~mm})$, periodontal attachment loss ( $\geq 4 \mathrm{~mm}$ ), and bleeding on probing. Chronic periodontitis was further stratified according to severity as follows: incipient (4 to $5 \mathrm{~mm}$ clinical attachment loss) and moderate/severe ( $\geq 6 \mathrm{~mm}$ clinical attachment loss). No dental radiographs were taken due to the special conditions of the patients. Periodontal health was determined when there was absence of obvious clinical inflammation, bleeding on probing, and no periodontal attachment loss.

\section{Subgingival Microbial Examination}

Subgingival plaque samples were obtained from the four deepest sites by inserting paper points in the sulcus/pocket bottom for 15 seconds and pooled in a vial containing viability-maintaining anaerobically prepared (VMGA III) transport medium. ${ }^{20}$ The samples were analyzed using microbial culture techniques for the presence of periodontopathic bacteria according to Doan et al. ${ }^{21}$ and Slots. ${ }^{22}$ Briefly, most samples were processed before 24 hours, taken at room temperature $\left(25^{\circ} \mathrm{C}\right)$, and immediately incubated in $\mathrm{CO}_{2}$ and anaerobic culture systems. Brucella blood agar medium enriched with $5 \%$ sheep blood and hemin menadione was incubated at $35^{\circ} \mathrm{C}$ in an anaerobic jar for 7 to 10 days. The trypticase soy-serum bacitracin vancomycin (TSBV) medium was incubated in $10 \% \mathrm{CO}_{2}$ in air at $37^{\circ} \mathrm{C}$ for 3 days. Presumptive identification was performed according to methods described by Slots and Reynolds ${ }^{23}$ and Rams et al. ${ }^{24}$ and by the use of a biochemical identification system for Actinobacillus actinomycetemcomitans, Porphyromonas gingivalis, Prevotella 
intermedia/nigrescens, Tannerella forsy thensis, Campylobacter spp, Eubacterium spp, Fusobacterium spp, Micromonas micros, Eikenella corrodens, Capnocytophaga spp, Dialister pneumosintes, $\beta$-hemolytic streptococci, Staphylococci spp, and yeasts. ${ }^{\ddagger}$ Total viable counts (TVC) were defined as the total number of colony forming units obtained on non-selective media plates. Species found on selective media were enumerated, and their percentage of TVC was calculated. Special attention was paid to the growth of Gram-negative enteric rods and yeasts on TSBV and Brucella agar. Gram-negative enteric rods were sub-cultured and colony purified on MacConkey and Cetrimide agar plates and identified using a commercial kit. $\S$

\section{Statistical Analysis}

A sample of 131 cases and 262 controls was calculated to detect differences with an $\alpha$ error of 0.05 and $\beta$ of 0.2 taking into account the prevalence of the periodontal disease in the 25- to 40-year-old group in Colombia (National Survey of Dental Health 1999 [ENSAB III]). The sample size was calculated using a statistical package. IInivariate and bivariate analysis were performed. Differences between continuous variables were evaluated with the two-tailed $t$ test for variables that were normally distributed and the Kruskall-Wallis test for variables that were not normally distributed. Chi-square or Fischer exact tests (if the smallest value was $<5$ ) were used to analyze differences in categoric variables. The odds ratios (ORs) and confidence intervals $(\mathrm{CI})$ were also calculated using a statistical package. . Statistical significance was estimated as $P$ $<0.05$.

\section{RESULTS}

The demographic and obstetric status of the study sample is depicted in Table 1. A total of 373 pregnant women were included, corresponding to 130 in the preeclamptic group and 243 in the nonpreeclamptic group, whereas $45 \%$ were pregnant for the first time. Most women (97.1\%) lived in urban residencies of low-level socioeconomic status. Twentynine percent $(28.7 \%)$ of the women only finished elementary school; most women $(70.8 \%)$ had a sec- ondary education level, and only two subjects $(0.5 \%)$ had a university education level.

Table 2 presents the blood pressure status in the preeclamptic and non-preeclamptic group. Women in the preeclamptic group had significantly high blood pressure (systolic blood pressure [SBP]: $137.7 \pm 17.4$ versus $104.7 \pm 11.1 \mathrm{~mm} \mathrm{Hg}$ and diastolic blood pressure [DBP]: $92.0 \pm 11.5$ versus $64.0 \pm 8.6 \mathrm{~mm} \mathrm{Hg})$ than the non-preeclamptic group $(P<0.001)$. Birth weight was also lower in preeclamptic women than in the control group $(2.453 \pm 634$ versus $2.981 \pm 783 \mathrm{~g} ; P<0.001)$.

Periodontal condition is presented in Table 3. Compared to controls, periodontal disease was more prevalent in the cases $(P \leq 0.001)$. Chronic periodontitis was more prevalent in the preeclamptic group (63.8\%) than in the non-preeclamptic group (36.6\%), and this difference reached statistical significance $(P \leq 0.001)$. When chronic periodontitis was considered according to severity, incipient periodontal destruction was observed in $42.3 \%$ of cases, whereas moderate/severe

‡ RapID ANA II System, Remel, Lenexa, KS

$\S$ API 20E system, BioMerieux, Hazelwood, MO.

I Epi-info statistical package, version 6.0, World Health OrganizationCenters for Disease Control and Prevention, Atlanta, GA

Il Epistat statistical package, version 3.0, Epistat, Richardson, TX. 
Table 2.

\section{Blood Pressure and Newborn Birth Weight in Preeclamptic and Non-Preeclamptic Women (mean $\pm \mathrm{SD})$}

\begin{tabular}{lccc}
\hline & $\begin{array}{c}\text { Preeclamptic } \\
(\mathrm{n}=130)\end{array}$ & $\begin{array}{c}\text { Non-Preeclamptic } \\
(\mathrm{n}=243)\end{array}$ & P Value* \\
\hline SBP $(\mathrm{mm} \mathrm{Hg})$ & $137.7 \pm 17.4$ & $104.7 \pm 11.1$ & $<0.001$ \\
DBP $(\mathrm{mm} \mathrm{Hg})$ & $92.0 \pm 11.5$ & $64.0 \pm 8.6$ & $<0.001$ \\
Birth weight $(\mathrm{kg})$ & $2453 \pm 634.6$ & $2981 \pm 783$ & $<0.001$ \\
\hline * Two-tailed $t$ test $(P \leq 0.05)$ & & &
\end{tabular}

* Two-tailed $t$ test $(P \leq 0.05)$.

Table 3.

\section{Periodontal Conditions and Clinical Parameters in Preeclamptic and Non-Preeclamptic Groups}

\begin{tabular}{|c|c|c|c|}
\hline & $\begin{array}{l}\text { Non-Preeclamptic } \\
\qquad \begin{array}{c}\mathrm{N}=243) \\
\mathrm{n}(\%)\end{array}\end{array}$ & $\begin{array}{l}\text { Preeclamptic } \\
(\mathrm{N}=130) \\
n(\%)\end{array}$ & P Value* \\
\hline \multicolumn{4}{|l|}{ Periodontal condition } \\
\hline Healthy/gingivitis & $154(63.4)$ & $47(36.2)$ & $<0.001$ \\
\hline Chronic periodontitis & $89(36.6)$ & $83(63.8)$ & $<0.001^{\dagger}$ \\
\hline Incipient (4 to 5 mm CAL) & $66(27.2)$ & $55(42.3)$ & $<0.001^{\ddagger}$ \\
\hline Moderate/severe ( $\geq 6 \mathrm{~mm} \mathrm{CAL})$ & $23(9.5)$ & $28(21.5)$ & $<\left.0.00\right|^{\S}$ \\
\hline \multicolumn{4}{|l|}{ Clinical parameters (mean \pm SE) } \\
\hline $\mathrm{PD}(\mathrm{mm})$ & $3.2 \pm 0.06$ & $4.1 \pm 0.09$ & $<\left.0.00\right|^{\|}$ \\
\hline $\mathrm{CAL}(\mathrm{mm})$ & $3.0 \pm 0.08$ & $4.0 \pm 0.10$ & $<0.001^{\ddagger}$ \\
\hline Tooth loss" & $2.7 \pm 0.30$ & $2.9 \pm 0.37$ & NS \\
\hline
\end{tabular}

NS = not statistically significant.

${ }^{*} \chi^{2}$ test.

$\dagger$ Chronic periodontitis versus preeclampsia, OR = 3.0 (95\% CI: 1.91 to $4.87 ; P<0.001)$.

\# Incipient periodontitis versus preeclampsia, $\mathrm{OR}=2.34$ (95\% $\mathrm{CI}: 1.47$ to $3.71 ; P<0.001)$.

$\S$ Moderate/severe periodontitis versus preeclampsia, $\mathrm{OR}=3.32$ (95\% $\mathrm{CI}: 1.79$ to $6.15 ; P<0.001)$

$\|$ Two-tailed $t$ test $(P \leq 0.05)$.

Il Number of teeth lost excluding third molars.

destruction was detected in $21.5 \%$ of preeclamptic women. The risk for women having periodontitis or attachment loss $\geq 4 \mathrm{~mm}$ to develop preeclampsia showed an OR of 3.0 (95\% CI: 1.91 to $4.86 ; P<0.001)$. A higher OR in preeclamptic women was observed with moderate/severe periodontitis (OR: 3.32; 95\% CI: 1.79 to $6.15 ; P<0.001)$. Only one subject out of 384 people studied was considered to be periodontally healthy. Additionally, more clinical attachment loss was found in the preeclamptic group compared to the control group $(4.0 \pm 0.10$ versus $3.0 \pm 0.08 \mathrm{~mm}$, respectively; $P<0.001)$.

The prevalence of $P$. gingivalis, $T$. forsythensis, and $E$. corrodens was higher in the preeclamptic group $(61.5 \%, 28.5 \%$, and $49.2 \%$, respectively) than the non-preeclamptic group $(P<0.01)$ (Table 4$)$. Bivari- ate analysis showed positive association between the risk of having preeclampsia and the presence of these pathogens (Fig. 1).

\section{DISCUSSION}

The results of this case-control study support the hypothesis that chronic periodontitis infection increases the risk of developing preeclampsia in pregnant women. These results also suggest that maternal chronic periodontal disease is a risk factor for children with low birth weight among preeclamptic women (cases) compared to non-preeclamptic women (controls). After evaluating the relationship between demographic, periodontal, subgingival microbiological factors, and preeclamptic disease in the present study, the following significant associations were found in the preeclamptic group: SBP, DBP, LBW $(P<0.001$; Table 2$)$, and chronic periodontitis $(P<0.001$; Table 3$)$. Differences in SBP, DBP, and LBW were expected, taking into account that preeclamptic women have high SBP and DBP and usually have preterm delivery or intrauterine growth restriction that increases the risk of having LBW. ${ }^{2}$ Regarding maternal periodontal disease, periodontitis is characterized by exacerbation periods interspersed with periods of remission and presents a local microbial burden that initiates local inflammation and local tissue destruction. ${ }^{25}$ It has been hypothesized that women with active periodontal disease during pregnancy may have transient translocation of oral bacteria to the maternal and fetal blood circulation, inciting placental inflammation or oxidative stress early in pregnancy, which ultimately produces placental damage and the clinical manifestations of preeclampsia. ${ }^{26,27}$ Interestingly, the OR for chronic periodontitis in the preeclamptic group was 3.0 (CI: 1.91 to 4.87 ) compared to the non-preeclamptic group. The presence of periodontal disease in pregnancy is not only seen among preeclamptic mothers because $36 \%$ of the non-preeclamptic group also had chronic periodontitis. Thus, the strong influences of periodontal disease on promoting the development of preeclampsia suggest that periodontal disease may represent a vascular stressor to the mother, placenta, and fetus. Furthermore, it was found that the possibility that mothers have preeclampsia increased with greater periodontal destruction (Table 3 ).

The mechanisms leading to preeclampsia are still poorly understood, and although abnormal 
Table 4.

Frequency Detection of Periodontopathic Bacteria According to Microbial Association in Preeclamptic and Non-Preeclamptic Groups

\begin{tabular}{|c|c|c|c|}
\hline Microorganism & $\begin{array}{c}\text { Preeclamptic } \\
(\mathrm{N}=130) \\
\mathrm{n}(\%)\end{array}$ & $\begin{array}{l}\text { Non-Preeclamptic } \\
\qquad \begin{array}{c}\mathrm{N}=243) \\
\mathrm{n}(\%)\end{array}\end{array}$ & $P$ Value* \\
\hline \multicolumn{4}{|l|}{ Red complex } \\
\hline P. gingivalis & $80(61.5)$ & | 18 (48.6) & 0.01 \\
\hline T. forsythensis & $37(28.5)$ & $44(18.1)$ & 0.01 \\
\hline \multicolumn{4}{|l|}{ Orange complex } \\
\hline P. intermedia/nigrescens & $75(57.7)$ & $127(52.3)$ & NS \\
\hline Fusobacterium spp & $110(84.6)$ & $199(81.9)$ & NS \\
\hline M. micros & $26(20.0)$ & $33(13.6)$ & NS \\
\hline Campylobacter spp & $33(25.4)$ & $45(18.5)$ & NS \\
\hline Eubacterium spp & $32(24.6)$ & $41(16.9)$ & NS \\
\hline \multicolumn{4}{|l|}{ Green complex } \\
\hline A. actinomycetemcomitans & $42(32.3)$ & $59(24.3)$ & NS \\
\hline E. corrodens & $64(49.2)$ & $85(35.0)$ & 0.007 \\
\hline \multicolumn{4}{|l|}{ Others } \\
\hline D. pneumosintes & $24(18.5)$ & $33(13.6)$ & NS \\
\hline Enteric rods & $28(21.7)$ & $43(17.7)$ & NS \\
\hline
\end{tabular}

NS $=$ not statistically significant.

${ }^{*} \chi^{2}$ test; $P$ values were not corrected for multiple endpoint analysis.

\section{Microorganism}

$$
\begin{gathered}
\text { Preeclamptic }(\mathrm{N}=130) \\
\text { OR }(95 \% \mathrm{Cl})
\end{gathered}
$$

\section{Red Complex}

$P$. gingivalis

T. forsythensis

$$
\begin{gathered}
1.77(1.12-2.80)^{*} \\
1.80(1.06-3.0)^{*}
\end{gathered}
$$

\section{Orange Complex}

$P$. intermedia/nigrescens

Fusobacterium spp

M. micros

Campylobacter spp

Eubacterium spp

\section{Green Complex}

A. actinomycetemcomitans

E. corrodens

$1.48(0.90-2.46)$

$1.80(1.14-2.84)^{\star}$

\section{Others}

D. pneumosintes

Enteric rods

$1.46(0.79-2.16)$

$1.28(0.73-2.26)$

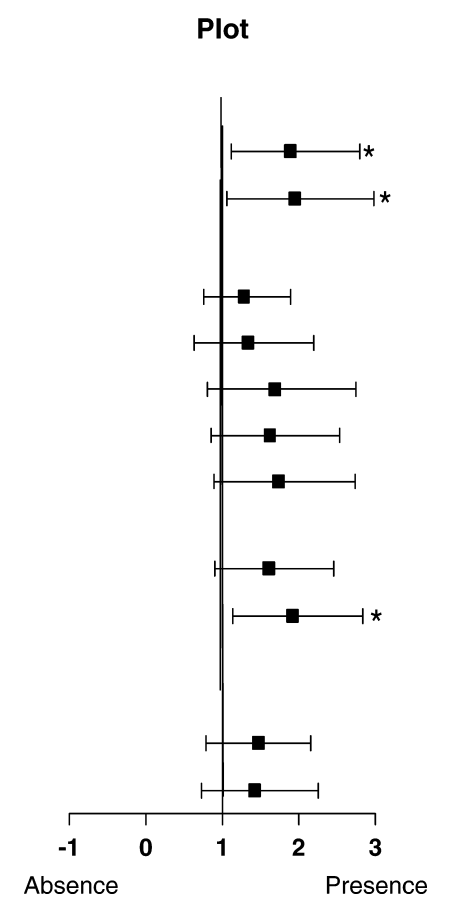

Figure I.

Odds ratio for the presence of periodontopathic bacteria according to microbial association complexes in the preeclamptic group $\left({ }^{*} \chi^{2}\right.$ test; $\left.\mathrm{P}<0.001\right)$. placentation occurs in impaired perfusion, it is not sufficient to cause the hypertension and proteinuria observed in preeclampsia. ${ }^{28}$ Endothelial cell dysfunction is a key feature of preeclampsia, potentially explaining the multiorgan nature of the disorder. This dysfunction is demonstrated by the structural changes in the placental bed and uterine boundary vessels and the high maternal blood levels of markers of endothelial damage such as fibronectin, von Willebrand factor, endothelin, tissue plasminogen activator, and thrombomodulin. ${ }^{29,30}$ An increase in oxidative stress due to reduced placental perfusion is a possible mediator of endothelial cell dysfunction. Placental ischemia is a common feature of preeclampsia and enhances the synthesis of inflammatory cytokines such as TNF- $\alpha$ that can induce oxidative damage. ${ }^{31} \mathrm{Un}$ der hypoxic conditions, free radicals of oxygen are formed that can stimulate lipid peroxidation of free fatty acids, leading to the injury of endothelial cells. Increased plasma levels of free 8-isoprostane, a marker of lipid peroxidation and a potent vasoconstrictor, have been observed in preeclamptic women. ${ }^{32}$ Recently, Beck and Offenbacher ${ }^{33}$ reported that periodontal disease is a vascular stressor as evidenced by increases in serum levels of soluble intercellular adhesion molecules (sICAMs).

It also has been hypothesized that normal pregnancy and preeclampsia are part of the same continuum, where pregnancy is accompanied by a mild proinflammatory state, and preeclampsia is characterized by a more severe level of inflammation. ${ }^{34}$ The immune system is downregulated in pregnancy, and the proinflammatory state in pregnancy may be necessary to protect the mother from infection. ${ }^{35}$ Periodontal disease may burden pregnant women systemically with endotoxin, inflammatory cytokines, and oxidative stressors at the maternal-fetus interface. Others have suggested that infection may be an important trigger of the inflammatory response that characterizes 
preeclampsia and may also initiate the preeclamptic process by increasing the risk for acute uteroplacental atherosis. ${ }^{36,37}$ Increasing evidence links periodontal disease and cardiovascular disease due to vascular endothelial dysfunction and atheroma formation. It is possible that similar mechanisms may also play roles in the developing of preeclampsia.

It is of interest that the subgingival presence of two red complex microorganisms ${ }^{38}(P$. gingivalis and $T$. forsythensis) and one green complex microorganism (E. corrodens) was more prevalent in the preeclamptic group (Table 4; Fig. 1). A number of experimental studies have linked virulence factors of $P$. gingivalis to complications in pregnancy outcome ${ }^{39-42}$ and the pathogenesis of atheroesclerosis. ${ }^{43}$ This Gramnegative periodontal pathogen may find its way into the bloodstream (bacteremia) in patients with periodontal disease as a result of oral hygiene procedures or even chewing. ${ }^{44,45}$ Furthermore, $P$. gingivalis has not only been found in the circulation but also in atherosclerotic plaques. ${ }^{46}$ The cysteine proteinases produced by $P$. gingivalis, termed gingipains, are considered to have potentially deleterious effects in activating coagulation factors and platelet aggregation ${ }^{47,48}$ and in altering the cytokine response in human umbilical-vein endothelial cells. ${ }^{49}$ Other important virulence factors of $P$. gingivalis are the fimbriae and lipopolysaccharide that can activate spleen cells and peripheral blood monocytes, resulting in the release of proinflammatory cytokines such as IL-1, IL6 , and TNF $-\alpha .{ }^{50,51}$ T. forsythensis possesses virulence traits, including the production of LPS and a trypsinlike protease, ${ }^{52}$ and the ability to penetrate and induce apoptosis in host cells. ${ }^{53}$ Taken together, this experimental evidence may explain, in part, the possible mechanisms of $P$. gingivalis and $T$. forsythensis virulence factors involved in preeclampsia development.

This study determined that periodontal disease is associated with preeclampsia and that two red complex microorganisms were more prevalent in the preeclamptic group. The results reported here provide additional evidence as to whether periodontal infection is linked to preeclampsia; however, further research is needed to support a causal association and its clinical implications.

\section{ACKNOWLEDGMENTS}

This investigation was supported by the Colombian Institute for Science and Technology (COLCIENCIAS; grant 1106-04-11992) and by the University of Valle. The authors thank Drs. Paula Colmenares, Olga Pacheco, Sandra Amaya, and Maria F. Bolaños (Periodontics Program, University of Valle) for their clinical assistance and Mrs. Senobia Buritica (Microbiology, University of Valle) for her laboratory assistance during the study.

\section{REFERENCES}

1. Paternoster DM, Fantinato S, Manganelli F, Nicolini U, Milani M, Girolami A. Recent progress in the therapeutic management of pre-eclampsia. Expert Opin Pharmacother 2004;5:2233-2239.

2. Ramos JG, Martins-Costa S, Edelweiss MI, Costa CA. Placental bed lesions and infant birth weight in hypertensive pregnant women. Braz J Med Biol Res 1995; 28:447-455.

3. Davison JM, Homuth V, Jeyabalan A, et al. New aspects in the pathophysiology of preeclampsia. J Am Soc Nephrol 2004;15:2440-2448.

4. Wolf M, Shah A, Jimenez-Kimble R, Sauk J, Ecker JL, Thadhani R. Differential risk of hypertensive disorders of pregnancy among Hispanic women. J Am Soc Nephrol 2004;15:1330-1338.

5. Freeman DJ, McManus F, Brown EA, et al. Short- and long-term changes in plasma inflammatory markers associated with preeclampsia. Hypertension 2004; 44:708-714.

6. Li X, Kolltveit KM, Tronstad L, Olsen I. Systemic diseases caused by oral infection. Clin Microbiol Rev 2000;13:547-558.

7. Hill JA, Devoe LD, Bryans CI Jr. Frequency of asymptomatic bacteriuria in preeclampsia. Obstet Gynecol 1986;67:529-532.

8. Abi-Said D, Annegers JF, Combs-Cantrell D, Frankowski RF, Willmore LJ. Case-control study of the risk factors for eclampsia. Am J Epidemiol 1995;142:437-441.

9. Hsu CD, Witter FR. Urogenital infection in preeclampsia. Int J Gynaecol Obstet 1995;49:271-275.

10. Mittendorf R, Lain KY, Williams MA, Walker CK. Preeclampsia. A nested, case-control study of risk factors and their interactions. J Reprod Med 1996;41:491-496.

11. Vallance P, Collier J, Bhagat K. Infection, inflammation, and infarction: Does acute endothelial dysfunction provide a link? Lancet 1997;349:1391-1392.

12. Socransky SS, Haffajee AD. Dental biofilms: Difficult therapeutic targets. Periodontol 2000 2002;28:12-55.

13. Lopez NJ, Smith PC, Gutierrez J. Higher risk of preterm birth and low birth weight in women with periodontal disease. J Dent Res 2002;81:58-63.

14. Offenbacher S, Katz V, Fertik G, et al. Periodontal infection as a possible risk factor for preterm low birth weight. J Periodontol 1996;67:1103-1113.

15. Davenport ES, Williams CE, Sterne JA, Murad S, Sivapathasundram V, Curtis MA. Maternal periodontal disease and preterm low birthweight: Case-control study. J Dent Res 2002;81:313-318.

16. Jeffcoat MK, Geurs NC, Reddy MS, Cliver SP, Goldenerg RL, Hauth JC. Periodontal infection and preterm birth: Results of a prospective study. J Am Dent AssoC 2001;132:875-880.

17. Boggess KA, Lieff S, Murtha AP, Moss K, Beck J, Offenbacher S. Maternal periodontal disease is associated with an increased risk for preeclampsia. Obstet Gynecol 2003;101:227-231.

18. Herrera JA, Chaudhuri G, Lopez-Jaramillo P. Is infection a major risk factor for preeclampsia? Med $\mathrm{Hy}$ potheses 2001;57:393-397.

19. Armitage GC. Development of a classification system for periodontal diseases and conditions. Ann Periodontol 1999;4:1-6.

20. Moller AJ. Microbiological examination of root canals and periapical tissues of human teeth. Methodological studies. Odontol Tidskr 1966;74(Suppl.):1-380. 
21. Doan N, Contreras A, Flynn J, Morrison J, Slots J. Proficiencies of three anaerobic culture systems for recovering periodontal pathogenic bacteria. J Clin Microbiol 1999;37:171-174.

22. Slots J. Rapid identification of important periodontal microorganisms by cultivation. Oral Microbiol Immunol 1986; $1: 48-57$.

23. Slots J, Reynolds HS. Long-wave UV light fluorescence for identification of black-pigmented Bacteroides spp. J Clin Microbiol 1982;16:1148-1151.

24. Rams TE, Feik D, Young V, Hammond BF, Slots J. Enterococci in human periodontitis. Oral Microbiol Immunol 1992; 7:249-252.

25. Goodson JM, Tanner AC, Haffajee AD, Sornberger GC, Socransky SS. Patterns of progression and regression of advanced destructive periodontal disease. $J$ Clin Periodontol 1982;9:472-481.

26. Madianos PN, Lieff S, Murtha AP, et al. Maternal periodontitis and prematurity. Part II: Maternal infection and fetal exposure. Ann Periodontol 2001;6:175-182.

27. Offenbacher S, Lieff S, Boggess KA, et al. Maternal periodontitis and prematurity. Part I: Obstetric outcome of prematurity and growth restriction. Ann Periodontol 2001;6:164-174.

28. Roberts JM. Preeclampsia: What we know and what we do not know. Semin Perinatol 2000;24:24-28.

29. Friedman SA, Lubarsky SL, Ahokas RA, Nova A, Sibai BM. Preeclampsia and related disorders. Clinical aspects and relevance of endothelin and nitric oxide. Clin Perinatol 1995;22:343-355.

30. Friedman SA, Schiff E, Emeis JJ, Dekker GA, Sibai BM. Biochemical corroboration of endothelial involvement in severe preeclampsia. Am J Obstet Gynecol 1995; 172:202-203.

31. Conrad KP, Benyo DF. Placental cytokines and the pathogenesis of preeclampsia. Am J Reprod Immunol 1997;37:240-249.

32. Barden A, Beilin LJ, Ritchie J, Croft KD, Walters BN, Michael CA. Plasma and urinary 8-iso-prostane as an indicator of lipid peroxidation in pre-eclampsia and normal pregnancy. Clin Sci (Lond) 1996;91:711-718.

33. Beck JD, Offenbacher S. The association between periodontal diseases and cardiovascular diseases: A stateof-the-science review. Ann Periodontol 2001;6:9-15.

34. Redman CW, Sacks GP, Sargent IL. Preeclampsia: An excessive maternal inflammatory response to pregnancy. Am J Obstet Gynecol 1999;180:499-506.

35. Faas MM, Schuiling GA. Pre-eclampsia and the inflammatory response. Eur J Obstet Gynecol Reprod Biol 2001;95:213-217.

36. von DP and Magee LA. Fall in mean arterial pressure and fetal growth restriction in pregnancy hypertension: An updated metaregression analysis. J Obstet Gynaecol Can 2002;24:941-945.

37. von DP and Magee LA. Could an infectious trigger explain the differential maternal response to the shared placental pathology of preeclampsia and normotensive intrauterine growth restriction? Acta Obstet Gynecol Scand 2002;81:642-648.

38. Socransky SS, Haffajee AD, Cugini MA, Smith C, Kent RL Jr. Microbial complexes in subgingival plaque. $J$ Clin Periodontol 1998;25:134-144.

39. Lin D, Smith MA, Elter J, et al. Porphyromonas gingivalis infection in pregnant mice is associated with placental dissemination, an increase in the pla- cental Th1/Th2 cytokine ratio, and fetal growth restriction. Infect Immun 2003;71:5163-5168.

40. Lin D, Smith MA, Champagne C, Elter J, Beck J, Offenbacher S. Porphyromonas gingivalis infection during pregnancy increases maternal tumor necrosis factor alpha, suppresses maternal interleukin-10, and enhances fetal growth restriction and resorption in mice. Infect Immun 2003;71:5156-5162.

41. Collins JG, Smith MA, Arnold RR, Offenbacher S. Effects of Escherichia coli and Porphyromonas gingivalis lipopolysaccharide on pregnancy outcome in the golden hamster. Infect Immun 1994;62:4652-4655.

42. Collins JG, WindleyArnold HWRR III, Offenbacher S. Effects of a Porphyromonas gingivalis infection on inflammatory mediator response and pregnancy outcome in hamsters. Infect Immun 1994;62:4356-4361.

43. Jain A, Batista EL Jr, Serhan C, Stahl GL, Van Dyke TE. Role for periodontitis in the progression of lipid deposition in an animal model. Infect Immun 2003; 71:6012-6018.

44. Silver JG, Martin AW, McBride BC. Experimental transient bacteraemias in human subjects with varying degrees of plaque accumulation and gingival inflammation. J Clin Periodontol 1977;4:92-99.

45. Carroll GC, Sebor RJ. Dental flossing and its relationship to transient bacteremia. J Periodontol 1980;51:691-692.

46. Haraszthy VI, Zambon JJ, Trevisan M, Zeid M, Genco RJ. Identification of periodontal pathogens in atheromatous plaques. J Periodontol 2000;71:1554-1560.

47. Lourbakos A, Yuan YP, Jenkins AL, et al. Activation of protease-activated receptors by gingipains from Porphyromonas gingivalis leads to platelet aggregation: A new trait in microbial pathogenicity. Blood 2001; 97:3790-3797.

48. Pham K, Feik D, Hammond BF, Rams TE, Whitaker EJ. Aggregation of human platelets by gingipain-R from Porphyromonas gingivalis cells and membrane vesicles. Platelets 2002;13:21-30.

49. Baba A, Kadowaki T, Asao T, Yamamoto K. Roles for Arg- and Lys-gingipains in the disruption of cytokine responses and loss of viability of human endothelial cells by Porphyromonas gingivalis infection. Biol Chem 2002;383:1223-1230.

50. Hamada S, Amano A, Kimura S, Nakagawa I, Kawabata S, Morisaki I. The importance of fimbriae in the virulence and ecology of some oral bacteria. Oral Microbiol Immunol 1998;13:129-138.

51. Lamont RJ, Jenkinson HF. Subgingival colonization by Porphyromonas gingivalis. Oral Microbiol Immunol 2000;15:341-349.

52. Moncla BJ, Braham P, Rabe LK, Hillier SL. Rapid presumptive identification of black-pigmented gramnegative anaerobic bacteria by using 4-methylumbelliferone derivatives. J Clin Microbiol 1991;29:1955-1958.

53. Arakawa $S$, Nakajima $T$, Ishikura $H$, Ichinose $S$, Ishikawa I, Tsuchida N. Novel apoptosis-inducing activity in Bacteroides forsythus: A comparative study with three serotypes of Actinobacillus actinomycetemcomitans. Infect Immun 2000;68:461 1-4615.

Correspondence: Dr. Adolfo Contreras, School of Dentistry, University of Valle, Calle 4B 36-00 San Fernando, Cali, Colombia. E-mail: inv-odon@univalle.edu.co.

Accepted for publication June 23, 2005. 